\title{
Effects of Thermal Processing on Microstructure in P/M Superalloys
}

\author{
Benjamin Bedard $^{1}$, Max A. Kaplan ${ }^{2}$, Mario P. Bochiechio ${ }^{2}$, and Mark Aindow ${ }^{1}$ \\ 1. Department of Materials Science and Engineering, and Institute of Materials Science, University of \\ Connecticut, Storrs, CT, USA \\ ${ }^{2 .}$ Materials \& Processes Engineering, Pratt \& Whitney, East Hartford, CT, USA
}

Powder metallurgy (P/M) nickel-based superalloys are designed to exhibit fine, homogeneous, stable microstructures which provide the excellent high temperature strength and creep resistance required in gas turbine engine disk applications. The microstructures comprise mainly a mixture of FCC $\gamma$-Ni and $\mathrm{L}_{0} \gamma^{\prime}-\mathrm{Ni}_{3} \mathrm{Al}$ phases with $<1 \%$ by volume of transition metal carbides and borides. The mechanical properties depend critically on the stability and distribution of these phases, so it is important to understand how the microstructures might develop during heat treatment from variations in high temperature holds.

In this study, we report the effects of heat treatments on the development of $\gamma$ ' phase distributions in the third-generation $\mathrm{P} / \mathrm{M}$ disk alloy ME-16 [1]. A heat-treated forging of the alloy was sectioned into $1 \mathrm{x} 1 \mathrm{x}$ $2 \mathrm{~cm}$ coupons, and these were isothermally exposed at temperatures between 800 and $1100^{\circ} \mathrm{C}$ for times of up to 168 hours with no external stress applied. Metallographic cross-sections were prepared from the coupons, and these were then etched to reveal the distributions of the $\gamma^{\prime}$ phase in the samples. Examples of secondary electron (SE) SEM images from the microstructure in the as-received material are shown in Fig. 1. The $\gamma$ grain size is around $10 \mu \mathrm{m}$, and there is a hierarchical distribution of the $\gamma^{\prime}$ phase including: coarse $(0.5-5 \mu \mathrm{m})$ primary $\gamma^{\prime}$ grains, smaller $(50-100 \mathrm{~nm})$ secondary $\gamma^{\prime}$, and very fine $(5-10$ $\mathrm{nm})$ tertiary $\gamma^{\prime}$. These latter two populations are present as precipitates in the $\gamma$ grains, as shown in higher magnification images such as Fig. 1B. There are also occasional bright particles corresponding to the inert carbides or borides (e.g. at $\mathrm{Y}$ in Fig. 1A).

Examples of the data from the samples exposed at 800,950 and $1100^{\circ} \mathrm{C}$ for times of 2,24 and $196 \mathrm{~h}$ are shown in Fig. 2. At $800^{\circ} \mathrm{C}$ the distribution of the $\gamma^{\prime}$ phase appears to be stable with only limited coarsening of the tertiery $\gamma^{\prime}$. At $950^{\circ} \mathrm{C}$, there is some dissolution of the tertiary $\gamma^{\prime}$, and this is accompanied by pronounced coarsening of the secondary $\gamma^{\prime}$. After $196 \mathrm{~h}$ at $1100^{\circ} \mathrm{C}$, only very fine $(<5$ $\mathrm{nm}) \gamma^{\prime}$ precipitates are observed within the $\gamma$ grains. This suggests that there is complete dissolution of the $\gamma^{\prime}$ phase at the heat-treatment temperature, and that these extremely fine precipitates are tertiary $\gamma^{\prime}$ formed on cooling to room temperature. The sizes and volume fractions of these $\gamma$ ' populations have been evaluated by image analysis and the results compared both to hardness measurements from the samples and to the $\gamma^{\prime}$ distributions expected on the basis of current precipitation models. These data provide a useful insight into the development of this microstructure during thermal processing, and potential microstructure evolution paths during heat treatment. [2]

\section{References:}

[1] P.L. Reynolds, US Patent \# US 8147749 B2.

[2] This research was supported in part by Pratt \& Whitney. The SEM experiments were performed in the UConn/FEI Center for Advanced Microscopy and Materials Analysis (CAMMA). 


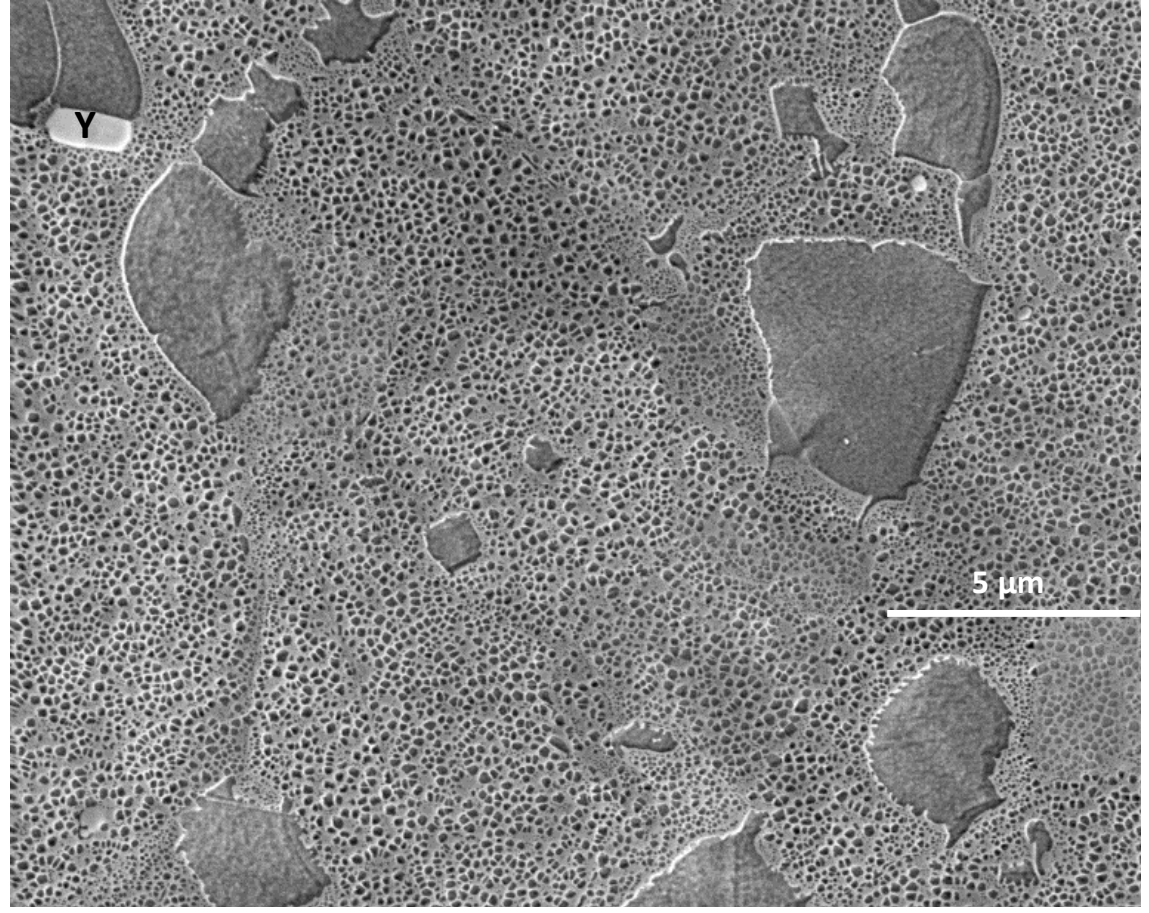

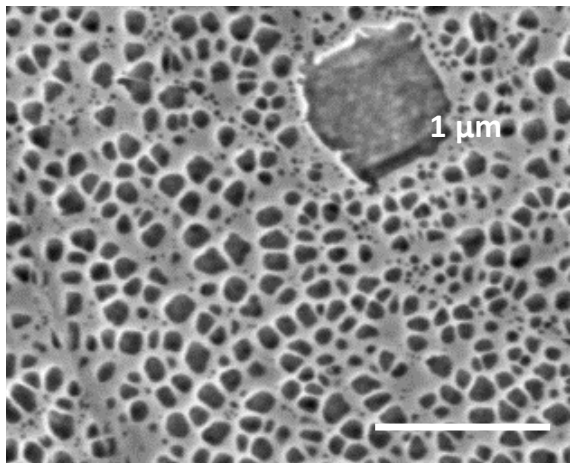

Figure 1. SE SEM images of the asreceived ME16 microstructure.

Primary and secondary $\gamma^{\prime}$ are visible in A and the finer tertiary $\gamma^{\prime}$ is visible between the secondary $\gamma^{\prime}$ precipitates in $\mathrm{B}$.

\section{$2 \mathrm{~h}$}

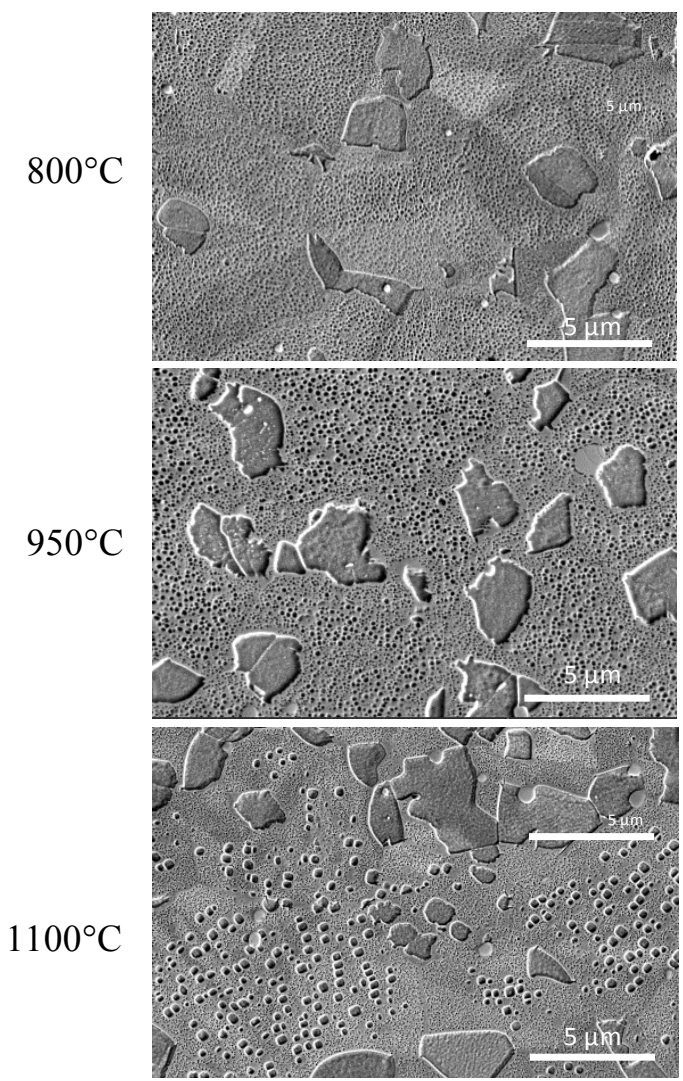

$24 \mathrm{~h}$
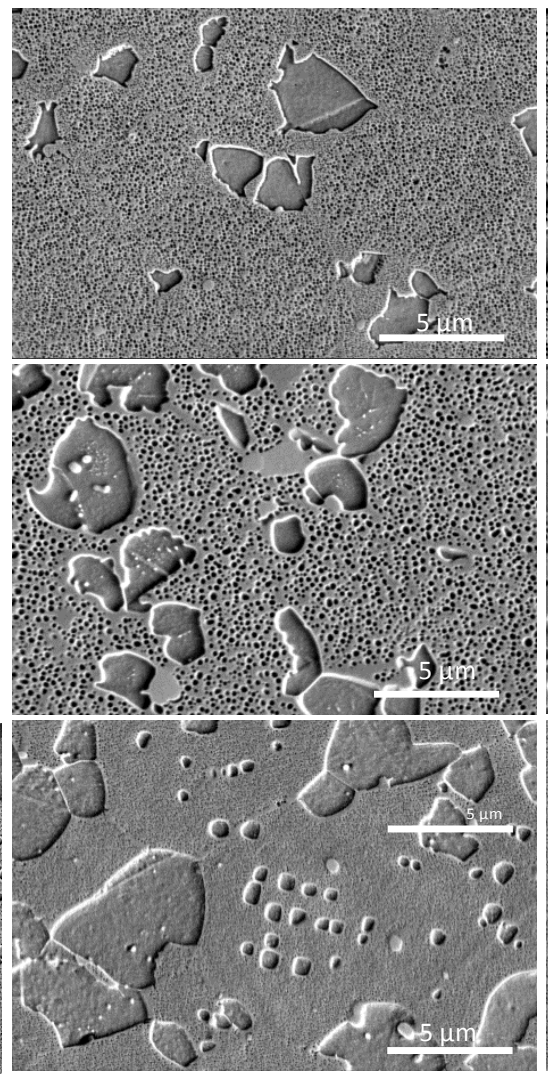

$168 \mathrm{~h}$

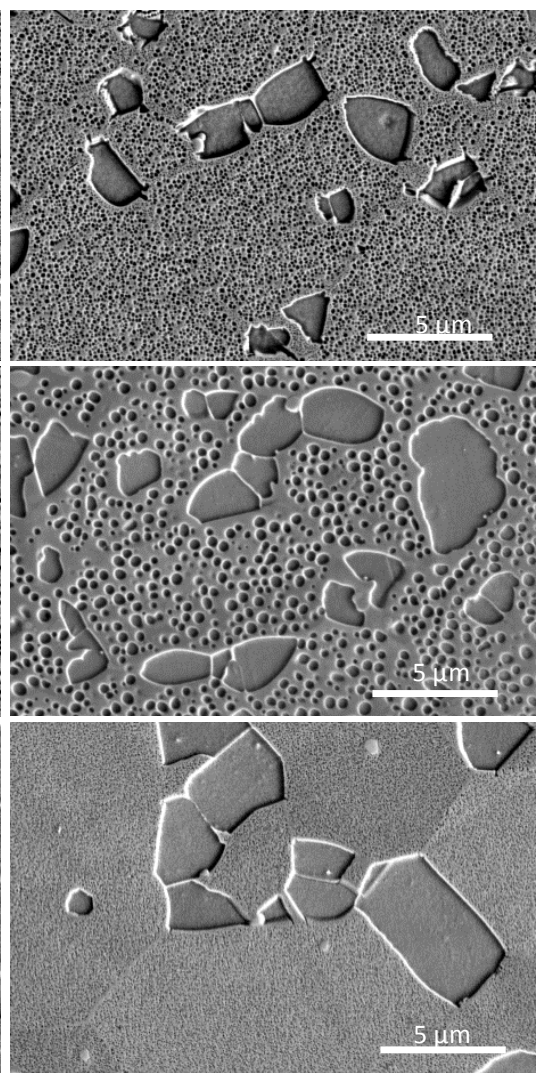

Figure 2. SE SEM images obtained from heat-treated samples of ME16. 